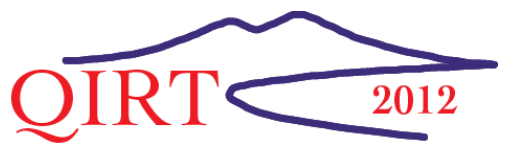

\title{
A Study on Detecting Defects in Slope Wall Thinning Specimens using optic infrared thermography
}

\author{
by W. T. Kim*, M. Y. Choi**, H. S. Park** and J. H. Park**
}

* Dev. of Mechanical and Automotive Engineering, Kongju National University, Cheonan, Korea, kwt@kongju.ac.kr **Safety Measurement Center, Korea Research Institute of Standards and Science, Daejeon, Korea, mychoi@kriss.re.kr, m55nring@naver.com, parkjh@kriss.re.kr

\begin{abstract}
This paper was purposed to detect the defects at the slope wall thinning of SM20C used in nuclear power plants using a thermographic system. To increase the detection rates of the defects, a lock-in method was used. As results, it was found that the probability of defect detection increases if the radiation time of the light source was fixed at $50 \mathrm{mHz}$ according to the slope depth of the specimen. The detection of an inclination defect at a $30^{\circ}$ angle was tested when the thickness of the specimen was $10 \mathrm{~mm}$. Additionally, it was difficult to detect a defect less than $20 \%$.
\end{abstract}

\section{Introduction}

Among infrared thermography nondestructive methods, there exist passive methods utilizing only infrared energy and active methods detecting defects by adding energy to the specimen and changing internal infrared radiation energy of the specimen. These active methods mainly include methods using optic wave, ultrasound, vibration, Eddy current, microwave, etc. For this research specifically, the optic infrared thermogrpahy [1,2]. As a method to remedy these issues, the IRT (Infrared Thermography Nondestructive Method) was adopted. As described early, IRT is a method to detect the infrared energy emitted by all objects above absolute temperature $0 \mathrm{~K}$, create an image that is visible to the test and examine it, which has a merit in examining a broad range within a short time being without making a contact. This study investigated the possibility of defect detection after manufacturing and investigated to be applicable for processing a flat panel specimen to examine the wall thinning defect that may occur in a nuclear power plant piping.

\section{Experimental configurations and apparatus}

For experimental configurations, Fig. 1(a) shows the saplings of the specimens and Fig. 2(b) displays the corresponding experimental IRT arrangement, respectively. A total of 9 slope wall thinning specimens as in Fig. 1(a) were manufactured by the precision processing of SM20C. The dimensions of one slope wall thinning specimen were as follows: $100 \mathrm{~mm}$ in diameter; $10 \mathrm{~mm}$ in thickness; 2, 4 and $8 \mathrm{~mm}$ in depth; $30^{\circ}$ in rake angle; 5, 10 and $20 \mathrm{~mm}$ in defect diameter, and one defect for each specimen was manufactured not the way in which there are various defects on one flat panel.

The base line of each specimen that is the angle diameter according to the depth, calculated by Pythagorean theorem. The principle of lock-in thermography is based on the idea that temperature modulation induced from outside the surface of the component propagates as a "thermal wave" inside the material. As this wave undergoes reflections at boundaries like all other waves, there could exist numerous reflected thermal waves.[3,4] An light-source two lamps with 1 $\mathrm{kW}$ in output and $2 \mathrm{~m}$ in distance was used, and the infrared camera was Silver 480M Model (NEDT: $25 \mathrm{mK}$ ) made by French Cedip Corp..

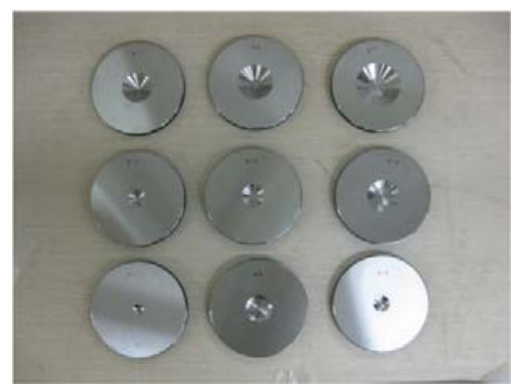

(a) geometry of specimens

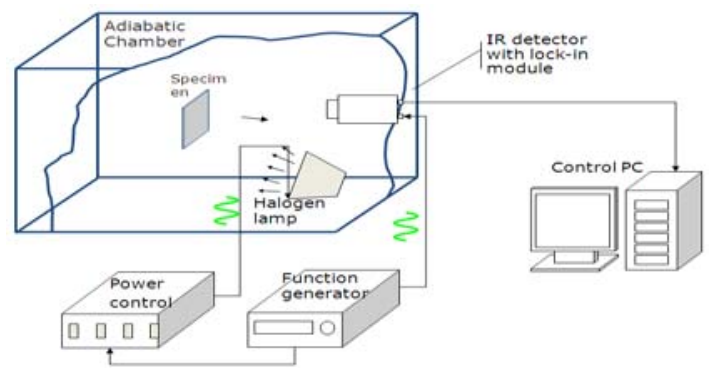

(b) system configuration

Fig. 1 Infrared thermography experiment system 
As for the materials used in this experiment, the possibility of detecting piping wall thinning defects was examined using SM20C with thermal properties similar to those of ASTM SA106 Gr.b used in the secondary nuclear piping. The properties of this specimen are shown in Table 1.

Table 1 Thermal properties specifications of SM20C

\begin{tabular}{|c|c|c|c|}
\hline $\begin{array}{c}\text { Conductive Heat transfer } \\
\text { coefficient(k) }\end{array}$ & Density $(\rho)$ & Specific heat(c) & Thermal Diffusivity $(\alpha)$ \\
\hline $51.9 \mathrm{~W} / \mathrm{m}^{-\mathrm{k}}$ & $7.87 \mathrm{~g} / \mathrm{cc}$ & $0.486 \mathrm{j} / \mathrm{g}^{-{ }^{\circ} \mathrm{C}}$ & $11.7 \times 10^{-6} \mathrm{~m}^{2} / \mathrm{s}$ \\
\hline
\end{tabular}

Considering that the wall thinning defect that occurs in piping does not have a fixed shape and contains a slopeshaped defect, this study manufactured a defect with quantified slope wall thinning unlike existing artificial defects and used it as a defect specimen. An experiment was carried out with the heating frequency at $50 \mathrm{mHz}$ of SM20C that has a lower heat transfer coefficient than SM45C that had been tested in existing papers.[5]

\section{Results}

As shown in Fig. 3(a), as a result of an experiment manufacturing slope wall thinning with a defect at $2 \mathrm{~mm}$ depth, it was difficult to obtain a significant defect image. As a result of an experiment manufacturing slope wall thinning with a defect depth of $4 \mathrm{~mm}$ like Fig. 3(b), whether there was a defect could be grasped in $20 \mathrm{~mm}$ and $10 \mathrm{~mm}$ diameters unlike the defect at $2 \mathrm{~mm}$ depth. As a result of an experiment manufacturing slop wall thinning with a defect at $8 \mathrm{~mm}$ depth like Fig. 3(c), defects could be grasped in 20,10 and $5 \mathrm{~mm}$ slop diameters unlike the slope wall thinning at $2 \mathrm{~mm}$ and $4 \mathrm{~mm}$ depths.

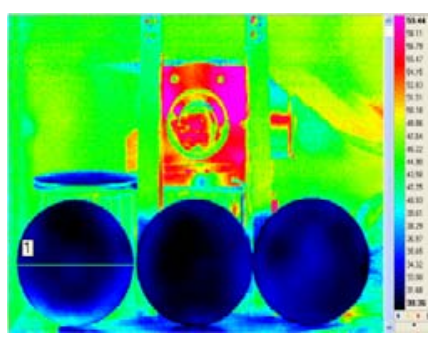

(a) Depth $2 \mathrm{~mm}$

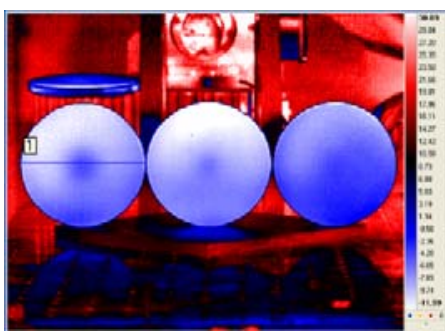

(b)Depth $4 \mathrm{~mm}$

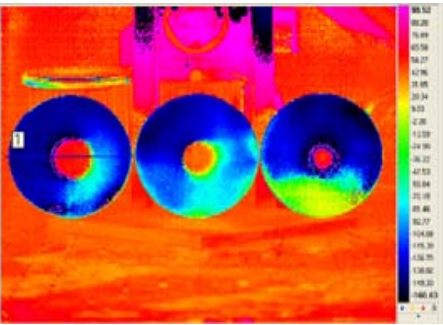

(c) Depth $8 \mathrm{~mm}$

Fig. 3 Imaging's of Lock-in Thermography for SM20C specimens

\section{Acknowledgements}

This work was supported by the Nuclear Research and Development of the Korea Institute of Energy Technology Evaluation and Planing (KETEP) grant funded by the Korea Government Ministry of Knowledge and Economy, and partially by the National Research Foundation of Korea(NRF) grant funded by the Korea government(MEST) (No. 2011-0026836)

\section{REFERENCES}

[1] Mignogna, R. B., Green, R. E. Jr., Duke, J. C. Jr., Henneke, EGII., Reifsnider, K. L., "Thermographic investigation of high-power ultrasonic heating in materials", Ultrasonics, (USA), Vol. 19, p. 159-163, 1981

[2] Zong, Mingcheng., Zhang, Jianxin. and Zhao, Yan., "Pulse-heating infrared thermography non-destructive testing technique", SPIE, (China), Vol. 2899, p. 654-659, 1996

[3] Busse, G., "Optoacoustic phase angle measurement for probing a metal."Appl. Phys.(Germany),Lett.35,p.759,1979

[4] Thomas, R. L., Pouch, J. J., Wong, Y. H., Favro, L. D. and Kuo, P. K., "Subsurface flaw detection in metals by photoacoustic microscopy." In: J. Appl. Phys. (USA), Vol. 51, p. 1152-1156, 1980

[5] Kang, K. S., Choi, M. Y., Park, J. H., Kim, W. T., "Analysis on thermoelastic stress in the cantilver beam by lock-in thermography", J. of Korean Society for Nondestructive Testing, (Korea), Vol. 28, No. 3, p. 273-278, 2008, 